Development of Self-Esteem and Relationship Satisfaction in Couples:

Two Longitudinal Studies

\author{
Ruth Yasemin Erol \\ University of Basel \\ Ulrich Orth \\ University of Bern
}

This article has been accepted for publication but has not been through the copyediting, typesetting, pagination, and proofreading process. This article may not exactly replicate the final version published in the journal. It is not the copy of record. Please cite this article as follows:

Erol, R. Y., \& Orth, U. (2014). Development of self-esteem and relationship satisfaction in couples: Two longitudinal studies. Developmental Psychology, 50, 2291-2303. http://dx.doi.org/10.1037/a0037370

Author Note

Ruth Yasemin Erol, Department of Psychology, University of Basel; Ulrich Orth, Department of Psychology, University of Bern.

This research was supported by Swiss National Science Foundation Grants PP00P1123370 to Ulrich Orth and CRSII1-147614 to Alexander Grob, Mike Martin, Franciska Krings, and Ulrich Orth.

Correspondence concerning this article should be addressed to Ruth Yasemin Erol, Department of Psychology, University of Basel, Missionsstrasse 62, 4055 Basel, Switzerland. Email: ruthyasemin.erol@unibas.ch. 


\begin{abstract}
We examined the effects of self-esteem development on the development of relationship satisfaction in two samples of couples. Study 1 used data from both partners of 885 couples assessed 5 times over 12 years, and Study 2 used data from both partners of 6,116 couples assessed 3 times over 15 years. The pattern of results was similar across the two studies. First, development of relationship satisfaction could be modeled as a couple-level process. Second, initial level of self-esteem of each partner predicted the initial level of the partners' common relationship satisfaction, and change in self-esteem of each partner predicted change in the partners' common relationship satisfaction. Third, these effects did not differ by gender and held when controlling for participants' age, length of relationship, health, and employment status. Fourth, self-esteem similarity among partners did not influence the development of their relationship satisfaction. The findings suggest that the development of self-esteem in both partners of a couple contributes in a meaningful way to the development of the partners' common satisfaction with their relationship.
\end{abstract}

Keywords: self-esteem, relationship satisfaction, common fate, growth curve modeling 


\section{Development of Self-Esteem and Relationship Satisfaction in Couples:}

Two Longitudinal Studies

Why are some couples more satisfied than others? Even though this question has been the focus of many studies for decades, no straightforward answer has been forthcoming. Relationship satisfaction is a construct influenced by multiple factors (Bradbury, Fincham, \& Beach, 2000), and emerging evidence suggests that self-esteem is one of these factors (e.g., Erol \& Orth, 2013; Murray, Holmes, \& Griffin, 2000; Orth, Robins, \& Widaman, 2012). However, the precise nature of the link between self-esteem and relationship satisfaction is still unclear. For example, does growing self-esteem of one of the partners in a relationship have a positive effect on both partners' satisfaction with the relationship? If so, do men and women differ in how their selfesteem influences relationship satisfaction? Does similarity in self-esteem in the two partners lead to a more satisfactory relationship? The present research aims to fill this gap by examining the link between development of self-esteem and development of relationship satisfaction, using data from both partners of couples who participated in two large longitudinal studies.

\section{Development of Relationship Satisfaction}

The construct of relationship satisfaction has been examined in a large body of research (for a review, see Bradbury et al., 2000). According to Bradbury et al. (2000), a major reason for the strong scientific interest in relationship satisfaction is its importance for personal and family well-being. The evidence suggests that being married or in a close relationship is related to higher levels of personal well-being (Diener, Suh, Lucas, \& Smith, 1999) and, moreover, that relationship satisfaction is one of the most predictive factors for relationship continuation (Hendrick, 1988; Hendrick, Hendrick, \& Adler, 1988). Nevertheless, some aspects of the construct are still controversially discussed. For example, some researchers define relationship satisfaction as a global evaluation of the marriage or close relationship (e.g., Fincham \& 
Bradbury, 1987), whereas others suggest that it is multidimensional, including evaluations of positive and negative aspects of the relationship (e.g., Hendrick, 1988; Spanier, 1976).

Researchers favoring the global definition argue that it avoids overlap between relationship satisfaction and its correlates such as the frequency of quarrels (Fincham \& Bradbury, 1987). In contrast, opponents of the global definition claim that evaluation of both positive and negative aspects is required for comprehensively covering the construct (Fincham \& Linfield, 1997). In the studies included in the present research, two different measures were employed, which corresponded to the two definitions described above. Whereas the measure used in Study 1captures positive and negative aspects of the relationship, in Study 2 the global satisfaction with the relationship was assessed. Therefore, if the results of the two studies converge, this will provide evidence for the robustness of the findings.

The trajectory of relationship satisfaction has been examined in several studies. Some studies reported a U-shaped curve with a decrease during the first years of the relationship and an increase in later years (e.g., Orbuch, House, Mero, \& Webster, 1996), whereas others found a continuous decrease across time (e.g., VanLaningham, Johnson, \& Amato, 2001) or found that it remained stable (e.g., Vaillant \& Vaillant, 1993). In addition, longitudinal studies are available that have examined the trajectories of relationship satisfaction over the first few years after marriage. Karney and Bradbury (1997) found a declining trajectory for both spouses, whereas Lavner and Bradbury (2010) reported that, although on average relationship satisfaction declined, a significant proportion of spouses experienced relatively high levels of relationship satisfaction and only small, if any, decline over time. Similarly, in a recent study Lavner, Bradbury, and Karney (2012) identified three distinct trajectories for husbands and wives: the first trajectory started high and remained stable, the second started at a moderate level and showed a small decline, and the third started low and showed a substantial decline. These findings suggest that 
decline in relationship satisfaction is limited to couples with a low level at the outset. Given that couples who experience declines in relationship satisfaction are more likely to dissolve the relationship in the future (Karney \& Bradbury, 1997), it is important to identify the factors that contribute to change in satisfaction.

According to the vulnerability-stress-adaptation model (Karney \& Bradbury, 1995), factors influencing relationship satisfaction can be grouped into three domains: personality traits and experiences prior to marriage (i.e., vulnerabilities), stressful events and circumstances during marriage (i.e., stressors), and emotions and communication skills during marriage (i.e., adaptation). This framework suggests that the satisfaction of a couple depends on how the couple deals with certain stressors during marriage, which is affected by the couple's prior traits and the quality of their social interaction (Bradbury \& Lavner, 2012). Several lines of research provide evidence for the propositions of the model. For the vulnerability domain, research indicates that low neuroticism (Karney \& Bradbury, 1997) and fewer premarital doubts (Lavner \& Bradbury, 2012) are related to relationship satisfaction. With regard to the stressors domain, stressful events (Lavner \& Bradbury, 2010) and higher psychological distress (Kurdek, 2005) predict lower relationship satisfaction. Influential factors in the adaptation domain include better communication (Meeks, Hendrick, \& Hendrick, 1998), less verbal and physical aggression (Lavner \& Bradbury, 2010), and greater love, trust, and cohesion (Kurdek, 2005). The findings reviewed above help to design interventions that account for a wide range of possible causes of low relationship satisfaction. However, with regard to high-risk couples, research suggests that it is particularly important to address additional factors such as low self-esteem to optimize the effectiveness of interventions (Lavner \& Bradbury, 2010). In the present research, we therefore focus on the role of self-esteem in the development of relationship satisfaction.

\section{The Link between Self-Esteem and Relationship Satisfaction}


Previous research suggests that self-esteem is positively related to relationship satisfaction (Fincham \& Bradbury, 1993; Murray, Holmes, \& Griffin, 1996; Shackelford, 2001).

Furthermore, in a 12-year longitudinal study with several waves of data, cross-lagged regression analyses indicated that self-esteem prospectively predicted relationship satisfaction; in contrast, relationship satisfaction did not predict self-esteem (Orth et al., 2012). Moreover, another longitudinal study found that self-esteem at Time 1 was correlated with relationship satisfaction at Time 2 in both men and women, whereas relationship satisfaction at Time 1 was correlated with self-esteem at Time 2 in men only (Fincham \& Bradbury, 1993). Also, Lavner, Bradbury, and Karney (2012) reported that initial differences in self-esteem distinguished between spouses with positive vs. negative trajectories of marital satisfaction. In sum, the available findings suggest that self-esteem has a positive effect on relationship satisfaction.

Thus, on the one hand the hypothesis that relationship satisfaction influences self-esteem has intuitive appeal, given that relationships — in particular attachment relationships — are assumed to be an important source of self-esteem (Swann \& Bosson, 2010). On the other hand, the available longitudinal evidence, as reviewed above, supports the reverse direction of effects, i.e., that self-esteem is a predictor of relationship satisfaction rather than vice versa (Fincham \& Bradbury, 1993; Orth et al., 2012). A possible reason for this pattern of results is that self-esteem is a relatively stable characteristic of individuals throughout the adult life span, comparable to broad personality traits such as the Big Five (Kuster \& Orth, 2013; Trzesniewski, Donnellan, \& Robins, 2003). Moreover, the pattern of results is consistent with research suggesting that selfesteem prospectively predicts satisfaction and success in other important life domains (besides relationships) such as work and health (Kuster, Orth, \& Meier, 2013; Orth et al., 2012). For these reasons, in the present research we focus on the possible influence of self-esteem on relationship satisfaction. 
When examining the link between self-esteem of relationship partners and the development of their relationship satisfaction, it is important to account for the fact that each partner's self-esteem itself changes over time. Although self-esteem is, as mentioned above, a relatively stable individual-differences construct, a growing body of evidence indicates that, on average, people experience systematic change in self-esteem across the life span. Longitudinal studies suggest that self-esteem increases throughout young and middle adulthood, peaking at about age 60 years, and then declines into old age (Erol \& Orth, 2011; Orth et al., 2012; Orth, Trzesniewski, \& Robins, 2010). Moreover, evidence suggests that throughout young and middle adulthood self-esteem not only increases but also becomes more stable and less contingent from daily events, or, to put it differently, self-esteem becomes better adjusted (Meier, Orth, Denissen, \& Kühnel, 2011). Possible causes of the normative changes in self-esteem across the life span are, for example, corresponding changes in the perceived control over one's life (Erol \& Orth, 2011) and changes in the individual's health and socioeconomic status (Orth et al., 2010).

Given these findings on systematic change in self-esteem during adulthood and given that in the present research we followed partners across 12 years (Study 1) and 15 years (Study 2), respectively, in the analyses we examined developmental changes in both self-esteem and relationship satisfaction. Thus, the analyses will answer the developmental question of how intraindividual change in self-esteem predicts intraindividual change in relationship satisfaction. Moreover, the present research capitalizes on the dyadic design of the data sets used. More specifically, the development of self-esteem among both partners of couples will be modeled as separate processes, which may independently predict the development of relationship satisfaction in these couples.

An important question is whether developmental processes in men's and women's selfesteem differentially affect the development of the couple's relationship satisfaction. On the one 
hand, meta-analytic findings indicate that men tend to have higher self-esteem than women, albeit the effect size is small (Kling, Hyde, Showers, \& Buswell, 1999). Moreover, due to the influence of gender stereotypes, it is possible that relationship harmony benefits from increasing selfesteem among men, but that relationship harmony is threatened by increasing self-esteem among women (admittedly, this hypothesis is purely speculative). In this case, the analyses would reveal that gender moderates the effect of self-esteem development on development of relationship satisfaction. On the other hand, cross-sectional research suggests that gender does not moderate the effect of an individual's self-esteem on his or her partner's satisfaction with the relationship (Erol \& Orth, 2013). Moreover, the methodological literature on dyadic analyses advises that researchers should be cautious in accepting hypotheses about gender differences before robust evidence is available (Ackerman, Donnellan, \& Kashy, 2011). Therefore, in this research we will test whether any gender differences that emerge replicate across the two studies.

In the analyses, it will be important to control for age and length of relationship, because these two variables could confound the relations between development of self-esteem and development of relationship satisfaction. For example, research suggests that both self-esteem and relationship satisfaction change in systematic ways across the adult life span (Orth et al., 2010; VanLaningham et al., 2001). Given that the samples examined in this research are heterogeneous with regard to age (see below for the description of the samples), and because, in contrast, many relationship partners are relatively homogeneous with regard to age, the relations between growth processes in self-esteem and relationship satisfaction could be artificially inflated or deflated. Similarly, it is possible that self-esteem and relationship satisfaction change systematically during the course of a relationship; again, because the samples examined are heterogeneous with regard to length of relationship, the relations between growth in self-esteem and relationship satisfaction could be biased, if length of relationship is not controlled for. 
In addition, it is possible that not only each individual's self-esteem but also the degree of the partners' similarity in self-esteem contributes to the couple's relationship satisfaction.

Overall, theory suggests that similarity rather than complementarity contributes to satisfaction with relationships, because similarity increases relationship functioning and reduces conflicts in daily life, and because similar partners share more similar emotional responses (Dyrenforth, Kashy, Donnellan, \& Lucas, 2010). Therefore, self-esteem similarity could facilitate empathy among relationship partners and lead to more positive social interaction. On the other hand, theory suggests that similarity in self-esteem could be also problematic, given the link between self-esteem and dominance (Zeigler-Hill, 2010). Research indicates that dominant people are more satisfied when interacting with submissive rather than dominant people, and, vice versa, that submissive people are more satisfied when interacting with dominant rather than submissive people (Dryer \& Horowitz, 1997). For these reasons, self-esteem similarity might be beneficial, detrimental, or the advantages and disadvantages of self-esteem similarity might cancel each other out. Empirical research indicates that the self-esteem of relationship partners is correlated at small to medium effect size (Erol \& Orth, 2013; Shackelford, 2001). However, previous research failed to test for possible effects of self-esteem similarity on relationship satisfaction. Although research has tested for the effects of similarity in other personality characteristics (such as the Big Five), similarity effects are still a topic of debate. Whereas some studies suggest that similarity in personality is related to relationship satisfaction (e.g., Gonzaga, Campos, \& Bradbury, 2007), other studies do not support this hypothesis (e.g., Donnellan, Assad, Robins, \& Conger, 2007) or report only very small similarity effects (Dyrenforth et al., 2010).

\section{The Present Research}

Our first goal was to examine whether the development of self-esteem in both partners predicted the development of a couple's relationship satisfaction. No previous study has tested 
for relations between the development of self-esteem and relationship satisfaction. Based on the findings of previous studies, we expected that for each partner a positive trajectory of self-esteem would predict a more positive trajectory of the couple's relationship satisfaction. Because crosscouple differences in age and length of relationship could confound the findings, in the analyses we controlled for the effects of these variables. In addition, we also tested whether the results hold when controlling for the effects of health and employment status. Our second goal was to test whether self-esteem similarity in a couple further contributes to the development of relationship satisfaction. Moreover, before conducting the main analyses, we tested whether development in relationship satisfaction can be modeled as a couple-level process. Specifically, we tested whether a common fate growth curve model (which combines the satisfaction ratings of both partners to form a single latent construct; Ledermann \& Kenny, 2012; Ledermann \& Macho, 2014) provides a good fit to the data. To answer these questions, we used data from two independent studies with large samples of couples and repeated assessments over long periods, which enables us to draw more accurate and generalizable conclusions.

\section{Study 1}

\section{Method}

Study 1 used data from the Longitudinal Study of Generations (LSG; Bengtson, 2009), which includes members of families that were randomly drawn from a subscriber list of about 840,000 members of a health maintenance organization in Southern California. Participants were assessed in 1971, 1985, 1988, 1991, 1994, 1997, and 2000. In 1971 and 1985, the LSG did not include the full self-esteem measure. Because growth curve analyses require that the same measure is available at each wave (Preacher, Wichman, MacCallum, \& Briggs, 2008), in the present research we used data of the five waves from 1988 to 2000 (denoted as Time 1 to Time 5). 
Participants. The sample consisted of 885 married or cohabiting couples (at Time 1, 98\% of the couples were married and $2 \%$ were cohabiting). For couples to be included in the present analyses, each partner had to provide data on at least one of the constructs examined in this research in at least one wave. Data were available for 690 couples at Time 1; 688 couples at Time 2; 758 couples at Time 3; 718 couples at Time 4; and 710 couples at Time 5. At Time 1, men's age ranged from 21 to 100 years $(M=54.3, S D=17.1)$ and women's age from 19 to 96 years $(M$ $=51.8, S D=16.7)$. Of the male participants, $91 \%$ were White, $3 \%$ were Hispanic, $1 \%$ were Black, and 5\% were from other ethnicities. Of the female participants, $94 \%$ were White, $3 \%$ were Hispanic, $1 \%$ were Black, and $2 \%$ were from other ethnicities. Because of the low frequencies of ethnicities other than White, we did not examine ethnic differences in Study 1. The length of relationship at Time 1 ranged from 1 to 62 years $(M=23.3, S D=15.9)$. To investigate the potential impact of attrition, we compared individuals who did and did not participate in the most recent wave of data collection (Time 5) on self-esteem and relationship satisfaction at the four preceding assessments. The only significant difference was that women who dropped out (versus those who did not) reported slightly lower relationship satisfaction at Time $3(d=-0.04)$; differences at Times 1, 2, and 4 (and for men at all assessments) were nonsignificant. Thus, nonrepresentativeness because of attrition was not a serious concern in this study.

Measures. Self-esteem was assessed with the 10-item Rosenberg Self-Esteem Scale (RSE; Rosenberg, 1965), a commonly used and well-validated measure of self-esteem (cf. Robins, Hendin, \& Trzesniewski, 2001). Responses were measured using a 4-point scale (ranging from 1 = strongly disagree to $4=$ strongly agree $)$. The mean averaged across waves was $3.42(S D$ $=0.43$ ) and the alpha reliability for men and women ranged from .81 to .87 across assessments.

Relationship satisfaction was assessed with the 10-item Gilford-Bengtson Marital Satisfaction Scale (Gilford \& Bengtson, 1979). Participants reported how frequently they 
experienced situations such as "laughing together" or "disagreeing about something important" (reverse-scored). Responses were measured on a 5-point scale (ranging from $1=$ hardly ever to 5 = almost always), with $M=3.92(S D=0.68)$ averaged across waves. The alpha reliability for men and women ranged from .86 to .89 across assessments. The favorable reliability estimates have been replicated in another study using the scale (Markides, Roberts-Jolly, Ray, Hoppe, \& Rudkin, 1999). To examine the convergent validity of the scale, we computed its correlation with a single-item measure of relationship satisfaction, which was included in the LSG in 1988, 1997, and 2000 ("Taking everything into consideration, how would you describe your marriage [or living arrangement] at this point in time?"). The correlation ranged from .70 to .80 across assessments, supporting the validity of the Gilford-Bengtson scale. For the analyses, we used the Gilford-Bengtson scale because it is a multi-item measure (typically, multi-item measures have better psychometric properties and, moreover, a reliability estimate was available only for the multi-item measure but not the single-item measure) and because the single item was available at only three waves.

Health was assessed with one item (i.e., "Compared to people your own age, how would you rate your overall physical health at the present time?"). Responses were measured on a 4point scale $(1=$ poor $; 4=$ excellent $)$, with $M=3.08(S D=0.75)$ averaged across waves. For employment status, we used a dichotomous variable (i.e., employed vs. unemployed).

Statistical analyses. The analyses were conducted using the Mplus 6.1 program (Muthén \& Muthén, 2010). To deal with missing values, we employed full-information maximum likelihood (FIML) estimation to fit models directly to the raw data, which produces less biased and more reliable results than conventional methods of dealing with missing data, such as listwise or pairwise deletion (Schafer \& Graham, 2002). Although full-information maximum likelihood methods are based on the assumption that data are at least "missing at random" (MAR) 
or "missing completely at random" (MCAR), even if data were "missing not at random" (MNAR) full-information maximum likelihood estimates are less biased compared to conventional methods of dealing with missing data (Allison, 2003). In both Study 1 and Study 2, we tested the effect of missing data on the results, by using multi-group models that compared couples who had no missing data (and stayed together across all waves) with couples who had missing data at some waves (e.g., due to divorce or because one of the partners was deceased). We computed two multi-group models: one in which the structural coefficients were estimated freely across groups and one in which the structural coefficients were constrained to be equal across groups. In both studies, the constraints did not significantly decrease model fit, suggesting that including couples with missing data did not confound the results. Model fit was assessed by the Tucker-Lewis index (TLI), the comparative fit index (CFI), and the root-mean-square error of approximation (RMSEA). Hu and Bentler (1999) suggest that good fit is indicated by values greater than or equal to .95 for TLI and CFI, and less than or equal to .06 for RMSEA. To test for differences in model fit, we used the test of small difference in fit recommended by MacCallum, Browne, and Cai (2006, Program C).

With regard to the RSE, a methodological problem in the LSG is that the labels of the middle response categories were slightly different in 1988 and 1991 (i.e., 2 = somewhat disagree and 3 = somewhat agree) vs. 1994, 1997, and 2000 (i.e., $2=$ disagree and $3=$ agree), which likely precludes measurement invariance of the raw scores across waves. As measurement invariance is essential for growth curve modeling (Edwards \& Wirth, 2009; Widaman, Ferrer, \& Conger, 2010), we used confirmatory factor analysis with categorical indicators (Wirth \& Edwards, 2007) and equating by common items (Edwards \& Wirth, 2009) to establish measurement invariance and to compute RSE factor scores. In these analyses, we followed the procedure described for the LSG by Orth et al. (2012). In short, the procedure establishes 
measurement invariance because all observed scores, by using common items as anchors, are mapped on the same latent scale. As in Orth et al. (2012), we equated the RSE across waves using two items from the Center for Epidemiologic Studies Depression Scale (CES-D; Radloff, 1977) that were conceptually related to self-esteem and that were available at each wave in identical response format (i.e., "I felt that I was just as good as other people" and "I thought my life had been a failure").

\section{Results and Discussion}

Table 1 shows means and standard deviations of the measures across waves, separately for men and women.

Common fate model of relationship satisfaction. Before examining the link between self-esteem and relationship satisfaction, we tested whether relationship satisfaction can be modeled as a common fate variable - that is, as a truly dyadic variable that captures variance common to both partners of a couple (Ledermann \& Kenny, 2012). The model included five latent relationship satisfaction factors (i.e., one for each of the five waves) that loaded onto the observed relationship satisfaction scores of both partners of the couple. The latent factors were allowed to correlate with each other. Moreover, the residuals of the indicators for each of the partners were correlated across waves to control for person-specific variance that was not captured by the dyadic latent factors. At each wave, the unstandardized loadings for both partners were set to $1 .^{1}$ The intercepts of one of the partners (i.e., the male partner) were set to 0 to identify the model. The fit of the model was good $(\mathrm{TLI}=.99, \mathrm{CFI}=1.00, \mathrm{RMSEA}=.025)$. The factor loadings were all significant $(p s<.05)$ and the standardized values ranged from .78 to .83 for men, and from .71 to .74 for women. Then, we tested for strong factorial invariance of the relationship satisfaction factors; strong factorial invariance is required when conducting growth curve analyses, because it ensures that the means of latent factors are measured on the same scale 
over time (Ledermann \& Kenny, 2012; Widaman et al., 2010). In this model, the intercepts of both partners were constrained to be equal within-person across waves. The fit of the model was good $(\mathrm{TLI}=.99, \mathrm{CFI}=1.00, \mathrm{RMSEA}=.023)$ and was not significantly worse than the fit of the model without constrained intercepts. Consequently, we used these constraints in subsequent analyses.

Next, we estimated a common fate growth curve model (Ledermann \& Macho, 2014) based on the latent relationship satisfaction factors, as measured in the model described above (Figure 1). The loadings of the intercept factor were set to 1 and the loadings of the slope factor were set to $0,0.25,0.5,0.75$, and 1 . The fit of the model was good $(\mathrm{TLI}=.98, \mathrm{CFI}=.99$, RMSEA $=.041) .{ }^{2}$ We also tested whether a quadratic growth curve model provided for a better fit to the data compared to the linear model (by including an additional slope factor, for which quadratic values of the loadings were used); however, the quadratic model did not converge properly. When we fixed the variance of the quadratic term to zero, the quadratic model converged but did not fit significantly better than the linear model (for the test of small difference in fit, $d f_{\text {linear }}=28, d f_{\text {quadratic }}=27$, critical $\Delta \chi^{2}=45.6$, observed $\left.\Delta \chi^{2}=1.3, n s\right)$. Consequently, we continued to use the linear model.

Main analyses. Then, we examined the effects of men's and women's self-esteem development on the development of relationship satisfaction. To model the growth processes of men's and women's self-esteem, we used a bivariate growth curve model (McArdle, 1988), which allows examining two parallel growth processes simultaneously (for an illustration, see the upper half of Figure 2). Specifically, the model included two sets of growth factors (i.e., one intercept and one slope factor for each of the two partners), which explained the corresponding self-esteem scores (i.e., men's and women's self-esteem). All growth factors were allowed to correlate with each other. The loadings of the intercept factors were set to 1 and the loadings of 
the slope factors were set to $0,0.25,0.5,0.75$, and 1 . The residual variances of self-esteem indicators were allowed to covary between men and women within waves to account for occasion-specific systematic variance. The fit of the model was good $(\mathrm{TLI}=.97, \mathrm{CFI}=.97$, RMSEA $=.067)$. We also tested whether a quadratic growth curve model provided for a better fit to the data than the linear model; however, the quadratic model did not fit significantly better than the linear model (for the test of small difference in fit, $d f_{\text {linear }}=36, d f_{\text {quadratic }}=34$, critical $\Delta \chi^{2}$ $=63.9$, observed $\left.\Delta \chi^{2}=0.9, n s\right)$.

Next, we examined the complete model, including self-esteem and relationship satisfaction (Figure 2). To model development in relationship satisfaction, we used the common fate growth curve model described above. The model included six growth factors: two intercept factors for self-esteem (i.e., men's and women's intercepts), two slope factors for self-esteem (i.e., men's and women's slope), and one intercept and one slope factor for relationship satisfaction. The growth factors (i.e., intercept and slope) for relationship satisfaction were regressed on the growth factors for self-esteem. In the analyses, we controlled for the effects of age and length of relationship, by regressing the growth factors for self-esteem and relationship satisfaction on the control variables (we used the mean age across both partners, given that the age of female and male partners was correlated at .98 averaged across waves).In both Study 1 and Study 2, the results were virtually unaltered when the control variables were not included in the models.

First, we estimated the effects of self-esteem on relationship satisfaction freely for men and women. Overall, the fit of the model was good (TLI $=.94$, CFI $=.96$, RMSEA $=.056)$. Second, we constrained the effects to be equal for men and women. The constraints did not significantly diminish model fit, suggesting that men and women did not differ in the effects of self-esteem development on relationship satisfaction. Consequently, in the remainder of the 
analyses, we used the model with cross-gender equality constraints on structural effects. Figure 3A shows the standardized estimates of the effects. The self-esteem intercept factors positively predicted the intercept factor of relationship satisfaction with about medium effect sizes (for both men and women, $\beta=.24, p<.05)$. Furthermore, the self-esteem slope factors positively predicted the slope factor of relationship satisfaction with about medium effect sizes (for men, $\beta=.24, p<$ .05 ; for women, $\beta=.23, p<.05){ }^{3}$ These findings suggest that higher initial levels of self-esteem predict a higher initial level of relationship satisfaction, and, more importantly, that positive changes in self-esteem predict positive change in relationship satisfaction. It is noteworthy that the effects of self-esteem intercepts were controlled for the effects of self-esteem slopes and, vice versa, the effects of self-esteem slopes were controlled for the effects of self-esteem intercepts, which strengthens the conclusions that can be drawn from the findings.

In addition, we tested whether age moderated the effects of self-esteem development on development of relationship satisfaction, using multi-group models (i.e., comparing participants who were, at Time 1, 40 years or younger vs. participants who were older than 40 years). Constraining the effects to be equal across groups did not significantly decrease model fit, suggesting that age did not moderate the effects. Similarly, we tested whether length of relationship satisfaction moderated the effects (comparing couples who were, at Time 1, less than 10 years together vs. couples who were more than 10 years together). The results suggested that length of relationship did not moderate the effects. Moreover, we tested whether the results hold when the participants' health and employment status were included as time-varying covariates in the model (i.e., using the wave-specific scores on these covariates); however, the results were essentially unaltered.

Finally, we tested whether similarity in self-esteem between partners has an effect on the development of relationship satisfaction. Similarity was operationalized as the difference between 
men's and women's self-esteem (thus, a difference of 0 indicates perfect similarity). On average, self-esteem did not differ between men and women $(M=0.01, S D=1.42$, averaged across waves; the positive mean indicates that men scored higher than women, although the difference was nonsignificant, $d=0.01)$. The wave-specific difference scores were used as indicators for a growth curve model, allowing us to examine whether the intercept and slope in self-esteem similarity predicted the growth factors of relationship satisfaction. The fit of this model was good $(\mathrm{TLI}=.96, \mathrm{CFI}=.97, \mathrm{RMSEA}=.044)$. However, neither the intercept nor the slope for selfesteem similarity had a significant effect on the growth factors for relationship satisfaction. Thus, the findings suggest that similarity in self-esteem does not influence the development of relationship satisfaction. To further test for effects of self-esteem similarity, we also used another indicator of similarity, by computing the absolute values of the difference between men's and women's self-esteem (i.e., discrepancy scores). When we examined a growth curve model using the wave-specific discrepancy scores, the fit of this model was good (TLI =.97, CFI = .97, RMSEA = .039). However, neither the intercept nor the slope factor of discrepancy scores significantly predicted the growth factors for relationship satisfaction.

\section{Study 2}

\section{Method}

Study 2 used data from the National Survey of Families and Households (NSFH; Sweet \& Bumpass, 2002), a nationally representative study providing a broad range of information on American family life. Participants were first assessed in 1987 or 1988 (Time 1), and then approx. 6 years (Time 2) and approx. 15 years (Time 3 ) later.

Participants. The sample consisted of 6,116 married or cohabiting couples (no information on the percentage of cohabiting couples is available). For couples to be included in the present analyses, each partner had to provide data on at least one of the constructs examined 
in this research in at least one wave. Data were available for 6,115 couples at Time 1; 3,956 couples at Time 2; and 1,836 couples at Time 3 (the assessment at Time 3 included only a small number of couples due to budget constraints; Sweet \& Bumpass, 2002). At Time 1, men's age ranged from 17 and 90 years $(M=43.0, S D=15.7)$ and women's age from 16 to 90 years $(M=$ $40.3, S D=15.2$ ). Of both male and female participants, $81 \%$ were White, $11 \%$ were Black, $7 \%$ were Hispanic, and 1\% were from other ethnicities. The length of relationship at Time 1 ranged from 0.8 to 68 years $(M=15.9, S D=15.1)$. To investigate the potential impact of attrition, we compared individuals who did and did not participate in the most recent wave of data collection (Time 3), on self-esteem and relationship satisfaction at the preceding assessments. At Time 1, men who dropped out (versus those who did not) reported slightly lower self-esteem $(M \mathrm{~s}=4.09$ vs. $4.12 ; d=-0.04)$, and women who dropped out reported slightly higher relationship satisfaction $(M \mathrm{~s}=6.06$ vs. $6.05 ; d=0.01)$. Given that these two differences were very small and, moreover, all other differences were nonsignificant, we concluded that nonrepresentativeness because of attrition was not a concern in this study.

Measures. Self-esteem was assessed with three items from the RSE. The items were "I feel that I am a person of worth, at least on an equal plane with others," "On the whole, I am satisfied with myself," "I am able to do things as well as other people." Responses were measured using a 5-point scale $(1=$ strongly agree $; 5=$ strongly disagree $)$, with $M=4.08(S D=$ 0.60) averaged across waves. The alpha reliability for men and women ranged from .60 to .68 across assessments.

Relationship satisfaction was assessed with one item (i.e., "Taking things all together, how would you describe your relationship?"). Responses were measured on a 7 -point scale $(1=$ very unhappy; $7=$ very happy), with $M=6.06(S D=1.22)$ averaged across waves.

Health was assessed with one item (i.e., "Compared with other people your own age, how 
would you describe your health?"). Responses were measured on a 5-point scale (1=very poor; 5 $=$ excellent $)$, with $M=4.01(S D=0.84)$ averaged across waves. For employment status, we used a dichotomous variable (i.e., employed vs. unemployed).

Statistical analyses. The analyses were conducted using the Mplus 6.1 program. Model fit was assessed using the same procedures as in Study 1.

\section{Results and Discussion}

Table 1 shows means and standard deviations of the measures across waves, separately for men and women. The models and statistical procedures were identical to Study 1, except that the Study 2 models were based on only three instead of five waves of data.

Common fate model for relationship satisfaction. As in Study 1, we tested whether relationship satisfaction can be modeled as a common fate variable. The model included three latent relationship satisfaction factors (i.e., one for each wave) that loaded onto the observed relationship satisfaction scores of both partners of the couple. The fit of the model was good (TLI $=1.00, \mathrm{CFI}=1.00, \mathrm{RMSEA}=.006)$. The factor loadings were all significant $(p \mathrm{~s}<.05)$ and standardized values ranged from .62 to .67 for men, and from .58 to .61 for women. Then, we tested for strong factorial invariance of relationship satisfaction, constraining the intercepts of both partners to be equal within-person across waves. The fit of the model was good (TLI = 1.00, $\mathrm{CFI}=1.00, \mathrm{RMSEA}=.000)$ and not significantly worse than the fit of the model without constrained intercepts. Consequently, we used these constraints in subsequent analyses.

Next, we estimated a common fate growth curve model based on the latent relationship factors, as measured in the model described above. The loadings of the intercept factor were set to 1 and the loadings of the slope factor were set to $0,0.4$, and 1 (corresponding to the timing of assessments). The fit of the model was acceptable $(\mathrm{TLI}=.89, \mathrm{CFI}=.94, \mathrm{RMSEA}=.058) .{ }^{4}$

Main analyses. We then examined the effects of men's and women's self-esteem 
development on the development of relationship satisfaction. As in Study 1, we used a bivariate growth curve model to capture change in men's and women's self-esteem. The loadings of the intercept factors were set to 1 and the loadings of the slope factors were set to $0,0.4$, and 1 . The fit of the model was acceptable $(\mathrm{TLI}=.95, \mathrm{CFI}=.99, \mathrm{RMSEA}=.034)$.

Next, we examined the complete model including the growth factors for relationship satisfaction regressed on the growth factors for self-esteem. First, we estimated the effects of selfesteem on relationship satisfaction freely for men and women. The fit of the model was good $(\mathrm{TLI}=.90, \mathrm{CFI}=.94, \mathrm{RMSEA}=.032)$. Second, we constrained the effects to be equal for men and women. The constraints did not significantly decrease model fit, suggesting that the effects did not differ between men and women. Consequently, in the remainder of the analyses, we used the model with cross-gender equality constraints. Figure 3B shows the standardized estimates of the structural effects. The self-esteem intercept factors positively predicted the intercept factor of relationship satisfaction with about medium effect sizes (for men, $\beta=.33, p<.05$; for women, $\beta$ $=.34, p<.05)$. Furthermore, the self-esteem slope factors positively predicted the slope factor of relationship satisfaction with about medium effect sizes (for men, $\beta=.26, p<.05$; for women, $\beta$ $=.22, p<.05)$. As in Study 1, these findings suggest that higher initial levels of self-esteem predict a higher initial level of relationship satisfaction, and, more importantly, that positive changes in self-esteem predict positive change in relationship satisfaction. In Study 2, two additional effects were significant given that the self-esteem intercepts negatively predicted the slope factor of relationship satisfaction (for both men and women, $\beta=-.17, p<.05$ ). However, the interpretation of effects of intercepts on slopes is often problematic. As in the present case, the growth process is often captured as it unfolds and, consequently, the location of the intercept is arbitrary and the intercept cannot be interpreted as the starting point of the process (Grimm, 2007). However, the size, and even the direction, of the relation between intercept and slope 
directly depend on the location of the intercept (Grimm, 2007). For this reason, and because the effect of the intercept on the slope emerged in only one of the two studies included in the present research, we did not draw substantive conclusions from these effects.

As in Study 1, we tested whether age moderated the effects of self-esteem development on development of relationship satisfaction, using multi-group models (i.e., comparing participants who were, at Time 1, 40 years or younger vs. participants who were older than 40 years). The results suggested that age did not moderate the effects. Similarly, we tested whether length of relationship satisfaction moderated the effects (comparing couples who were, at Time 1, less than 10 years together vs. couples who were more than 10 years together). Again, the results suggested that length of relationship did not moderate the effects. ${ }^{5}$ We also tested whether ethnicity moderated the effects of self-esteem development on development of relationship satisfaction, using multi-group models (i.e., we compared 4,710 couples of which both partners were White, 649 couples of which both partners were Black, and 472 couples of which both partners were Hispanic). Constraining the effects to be equal across groups did not significantly decrease model fit, suggesting that ethnicity did not moderate the effects. ${ }^{6}$ Moreover, as in Study 1, we tested whether the results hold when health and employment status were included as timevarying covariates; however, the results were essentially unaltered.

Finally, we tested whether similarity in self-esteem between partners — as indicated by difference scores — had an effect on the development of relationship satisfaction (TLI $=.87$, CFI $=.92$, RMSEA $=.045)$. On average, men reported slightly higher self-esteem than women $(M=$ $0.08, S D=1.31$, averaged across waves; $p<.05, d=0.06)$. However, neither the intercept nor the slope factor for self-esteem similarity had a significant effect on the growth factors for relationship satisfaction. Thus, as in Study 1, the findings suggest that similarity in self-esteem does not influence the development of relationship satisfaction. Again, we further tested for 
effects of self-esteem similarity by using the absolute values of the difference between men's and women's self-esteem (i.e., discrepancy scores) as indicators for a growth curve model (TLI = .89, $\mathrm{CFI}=.93, \mathrm{RMSEA}=.038)$. However, the intercept and slope factor of discrepancy scores did not significantly predict the growth factors for relationship satisfaction (except for the effect of the intercept of self-esteem discrepancy on the intercept of relationship satisfaction, which was -.26, $p<.05)$.

\section{General Discussion}

In the present research, we examined the effects of self-esteem development on the development of relationship satisfaction in two samples of couples. Study 1 used data from both partners of 885 couples assessed 5 times over 12 years, and Study 2 used data from both partners of 6,116 couples assessed 3 times over 15 years. The pattern of results was similar across the two studies. First, development of relationship satisfaction could be modeled as a couple-level process. Second, initial level of self-esteem of each partner predicted the initial level of the partners' common relationship satisfaction, and change in self-esteem of each partner predicted change in the partners' common relationship satisfaction. Third, these effects did not differ by gender and held controlling for participants' age, length of relationship, health, and employment status. Fourth, self-esteem similarity among partners did not influence the development of their relationship satisfaction. In the following, we discuss these findings in more detail.

The results suggest that relationship satisfaction can be modeled as a truly dyadic variable. Specifically, in our analyses we combined the satisfaction ratings of both partners of a couple to form a single - i.e., couple-level—latent construct, using the common fate model (Ledermann \& Kenny, 2012). Then, we assessed the developmental trajectory of relationship satisfaction using a common fate growth curve model (Ledermann \& Macho, 2014). For both data sets examined in this research, the results supported the usefulness of the model: (a) the fit of 
the model was good and (b) the loadings of the couple-level factors on the individual-level indicators were large. The findings support that — at least in the data sets examined in this research—men's and women's reports of relationship satisfaction are highly related and can be used to model a dyadic variable.

In both studies, the analyses showed that the developmental trajectories of self-esteem of each partner predicted the developmental trajectory of the couple's common relationship satisfaction. Although previous studies had suggested that self-esteem prospectively predicts the individual's relationship satisfaction and, moreover, although cross-sectional research indicates that self-esteem is linked in a dyadic way to relationship satisfaction (Erol \& Orth, 2013; Murray et al., 2000), no previous study has tested whether change in self-esteem is related to change in the couple's satisfaction. By using growth curve modeling of longitudinal data, the present research suggests that the developmental trajectories of self-esteem and relationship satisfaction (i.e., in particular their slope factors) are meaningfully related within couples. When we regressed the growth factors for relationship satisfaction on growth factors for self-esteem, the effects were of about medium size. Importantly, given that we simultaneously examined the effects of both partners' self-esteem, the cumulative effects of the partners' self-esteem on relationship satisfaction are twice as large as the individual effects of self-esteem.

In both studies the effect sizes did not differ significantly between male and female partners. Thus, although men and women might differ in their typical social roles (Eagly \& Wood, 1999) and although it might be plausible that change (e.g., improvement) in men's and women's self-esteem differentially affects the couple's harmony, the present findings suggest that the structural relations between self-esteem and relationship satisfaction hold across gender, corresponding to results from cross-sectional dyadic analyses (Erol \& Orth, 2013). Moreover, the findings are in line with longitudinal results reported by Kurdek (2005) who examined whether 
there is a "his or her version of marital processes" (p. 82). Kurdek (2005) concluded that although men and women differ in average levels on variables such as marriage-specific appraisals and satisfaction with social support by the partner, the effects of these variables on relationship satisfaction were similar for men and women (Kurdek, 2005).

The present research rules out an additional, or alternative, hypothesis on the relation between development in self-esteem and relationship satisfaction, specifically the hypothesis that the partners' similarity in self-esteem contributes to the development of relationship satisfaction. In both studies, level and change in self-esteem similarity was not significantly related to the developmental trajectory of relationship satisfaction. Thus, the findings on self-esteem similarity are largely consistent with studies on similarity in other personality characteristics, many of which suggested that similarity does not influence, or has negligible effects on, the couple's relationship satisfaction (Donnellan, Trzesniewski, Conger, \& Conger, 2007; Dyrenforth et al., 2010). As outlined in the Introduction, there are competing theoretical perspectives suggesting that self-esteem similarity could be either beneficial for relationships (because partners share more similar emotional responses) or detrimental (because high self-esteem is linked to a dominant interpersonal style and because dominant people are more satisfied when interacting with submissive rather than dominant partners). Consequently, it is possible that we did not find an effect of self-esteem similarity because its advantages and disadvantages cancel each other out. Another perspective is provided by Murray, Holmes, Bellavia, Griffin, and Dolderman (2002) who argue that couples perceive similarity even when in reality the similarity is small, but that the mere perception of similarity is sufficient to feel better understood and, consequently, to be more satisfied with the relationship. Therefore, perceiving to have similar self-esteem might be more important than actual similarity for a satisfying relationship.

A limitation of this research is that the study designs, although longitudinal, do not allow 
for causal conclusions about the effects of self-esteem on the development of relationship satisfaction. As in all non-experimental studies, effects may be caused by third variables that were not included in the analyses. However, given that we controlled for several relevant variables that could have confounded the self-esteem effect (i.e., age, length of relationship, health, and employment status), the present research strengthens the case for the unique effect of self-esteem on relationship satisfaction.

Another limitation is that both data sets examined in this research included participants from a single country, i.e., the United States. Although the findings are likely to generalize to other Western countries, future research should replicate the analyses using samples from other cultural contexts. For example, research suggests that culture influences communication behaviors in relationships and, moreover, influences whether these behaviors are linked to relationship satisfaction (Williamson et al., 2012). However, in Study 2 it was possible to test for ethnic differences and the results suggested that the findings did not differ between White, Black, and Hispanic participants. Thus, although the participants of Study 2 were American, the fact that the pattern of results replicated across different ethnic groups is a first step toward establishing the cross-cultural generalizability of the findings. Nevertheless, future research is needed to examine differences that may exist within Hispanic (e.g., Puerto Rican, Mexican, etc.) and Black (e.g., African American, Caribbean, etc.) populations to better understand how generalizable the present findings are.

In Study 2, self-esteem was measured using only three items of the RSE. Therefore, as expected, the reliability of this measure was lower compared to the 10-item RSE (Robins et al., 2001). However, in the LSG data set used in Study 1, the three-item RSE (as used in Study 2) correlated at .80 with the 10-item RSE, supporting the validity of the three-item RSE. In addition, based on an item response analysis, Gray-Little, Williams, and Hancock (1997) suggested that 
the 10-item RSE "could be shortened without compromising the measurement of global selfesteem" (p. 450).

One strength of the present research is the convergence of findings across Studies 1 and 2, which helps allay some methodological concerns. For example, a limitation of Study 2 was that self-esteem was assessed with only three items (as mentioned above) and relationship satisfaction with a single item; however, this limitation was addressed in Study 1, in which the complete 10item RSE and a 10-item scale for relationship satisfaction was used. A limitation of Study 1 was that the sample was not representative of the U.S. population; however, this limitation was addressed in Study 2, in which data from a national probability sample were used, increasing confidence in the generalizability of our findings. Additional strengths of the present research are that both studies included very large samples of couples and that the samples were heterogeneous with regard to the participants' age (ranging from 16 to 96 years across studies) and length of relationship (ranging from 0.8 to 68 years across studies). Also, in both studies participants were repeatedly assessed across long periods (12 years in Study 1 and 15 years in Study 2).

As yet there is scant evidence with regard to the mechanisms that account for the link between self-esteem and relationship satisfaction. The study by Murray et al. (2000) suggested that felt security about the partner's love might mediate the effect of self-esteem on relationship satisfaction. More specifically, individuals with low self-esteem tend to think that their partners see them as negatively as they see themselves; therefore, in order to avoid disappointment, they might defensively find faults in their partner or distance themselves, which in turn diminishes both partners' satisfaction with the relationship. Furthermore, a study by Erol and Orth (2013) found that secure romantic attachment between the partners mediated large portions of actor and partner effects of self-esteem on relationship satisfaction. Secure romantic attachment to the current partner was assessed as having low levels of attachment-related anxiety and avoidance, 
both of which contributed independently to the mediation effect. Possible theoretical explanations for the mediating effects are that, for example, attachment-related anxiety is linked to problematic interpersonal behavior such as excessive reassurance seeking (Shaver, Schachner, \& Mikulincer, 2005), whereas attachment-related avoidance is linked to paying less attention to emotional information provided by the partner (Fraley, Garner, \& Shaver, 2000). Therefore, in future research, it would be of interest to test whether growth in secure attachment between the partners mediates the effects of growth in self-esteem on growth in relationship satisfaction. Moreover, it is possible that the degree of attachment security is related to whether couples are married or cohabiting; future research should therefore explore the role of marital status in the link between self-esteem and relationship satisfaction.

In conclusion, the present research suggests that the development of self-esteem among relationship partners influences the development of their common relationship satisfaction, regardless of the partners' age, the length of their relationship, and the similarity of their selfesteem. The findings contribute to the emerging understanding of the link between self-esteem and satisfaction in romantic relationships. Furthermore, the findings suggest that interventions aimed at improving self-esteem may be an effective way to enhance a couple's relationship satisfaction and, consequently, increase the stability of their relationship. Given that the findings indicate that each partner's self-esteem has a unique effect on the couple's satisfaction, not only interventions that target both partners' self-esteem (e.g., in the context of relationship counseling), but also interventions that focus on one of the partners might contribute to the quality of the relationship. 


\section{References}

Ackerman, R. A., Donnellan, M. B., \& Kashy, D. A. (2011). Working with dyadic data in studies of emerging adulthood: Specific recommendations, general advice, and practical tips. In F. D. Fincham \& M. Cui (Eds.), Romantic relationships in emerging adulthood. New York, NY: Cambridge University Press.

Allison, P. D. (2003). Missing data techniques for structural equation modeling. Journal of Abnormal Psychology, 112, 545-557.

Bengtson, V. L. (2009). Longitudinal Study of Generations, 1971, 1985, 1988, 1991, 1994, 1997, 2000 [Data file and codebook]. Ann Arbor, MI: Inter-University Consortium for Political and Social Research [Distributor].

Bradbury, T. N., Fincham, F. D., \& Beach, S. R. H. (2000). Research on the nature and determinants of marital satisfaction: A decade in review. Journal of Marriage and Family, 62, 964-980.

Bradbury, T. N., \& Lavner, J. A. (2012). How can we improve preventive and educational interventions for intimate relationships? Behavior Therapy, 43, 113-122.

Diener, E., Suh, E. M., Lucas, R. E., \& Smith, H. L. (1999). Subjective well-being: Three decades of progress. Psychological Bulletin, 125, 276-302.

Donnellan, M. B., Assad, K. K., Robins, R. W., \& Conger, R. D. (2007). Do negative interactions mediate the effects of negative emotionality, communal positive emotionality, and constraint on relationship satisfaction? Journal of Social and Personal Relationships, 24, $557-573$.

Donnellan, M. B., Trzesniewski, K. H., Conger, K. J., \& Conger, R. D. (2007). A three-wave longitudinal study of self-evaluations during young adulthood. Journal of Research in Personality, 41, 453-472. 
Dryer, D. C., \& Horowitz, L. M. (1997). When do opposites attract? Interpersonal complementarity versus similarity. Journal of Personality and Social Psychology, 72, 592-603.

Dyrenforth, P. S., Kashy, D. A., Donnellan, M. B., \& Lucas, R. E. (2010). Predicting relationship and life satisfaction from personality in nationally representative samples from three countries: The relative importance of actor, partner, and similarity effects. Journal of Personality and Social Psychology, 99, 690-702.

Eagly, A. H., \& Wood, W. (1999). The origins of sex differences in human behavior: Evolved dispositions versus social roles. American Psychologist, 54, 408-423.

Edwards, M. C., \& Wirth, R. J. (2009). Measurement and the study of change. Research in Human Development, 6, 74-96.

Erol, R. Y., \& Orth, U. (2011). Self-esteem development from age 14 to 30: A longitudinal study. Journal of Personality and Social Psychology, 101, 607-619.

Erol, R. Y., \& Orth, U. (2013). Actor and partner effects of self-esteem on relationship satisfaction and the mediating role of secure attachment between the partners. Journal of Research in Personality, 47, 26-35.

Fincham, F. D., \& Bradbury, T. N. (1987). The assessment of marital quality: A reevaluation. Journal of Marriage and the Family, 49, 797-809.

Fincham, F. D., \& Bradbury, T. N. (1993). Marital satisfaction, depression, and attributions: A longitudinal analysis. Journal of Personality and Social Psychology, 64, 442-452.

Fincham, F. D., \& Linfield, K. J. (1997). A new look at marital quality: Can spouses feel positive and negative about their marriage? Journal of Family Psychology, 11, 489-502.

Fraley, R. C., Garner, J. P., \& Shaver, P. R. (2000). Adult attachment and the defensive regulation of attention and memory: Examining the role of preemtive and postemptive 
defensive processes. Journal of Personality and Social Psychology, 79, 816-826.

Gilford, R., \& Bengtson, V. (1979). Measuring marital satisfaction in three generations: Positive and negative dimensions. Journal of Marriage and Family, 41, 387-398.

Gonzaga, G. C., Campos, B., \& Bradbury, T. N. (2007). Similarity, convergence, and relationship satisfaction in dating and married couples. Journal of Personality and Social Psychology, 93, 34-48.

Gray-Little, B., Williams, V. S. L., \& Hancock, T. D. (1997). An item response theory analysis of the Rosenberg Self-Esteem Scale. Personality and Social Psychology Bulletin, 23, 443451.

Grimm, K. J. (2007). Multivariate longitudinal methods for studying developmental relationships between depression and academic achievement. International Journal of Behavioral Development, 31, 328-339.

Hendrick, S. S. (1988). A generic measure of relationship satisfaction. Journal of Marriage and the Family, 50, 93-98.

Hendrick, S. S., Hendrick, C., \& Adler, N. L. (1988). Romantic relationships: Love, satisfaction, and staying together. Journal of Personality and Social Psychology, 54, 980-988.

Hu, L., \& Bentler, P. M. (1999). Cutoff criteria for fit indexes in covariance structure analysis: Conventional criteria versus new alternatives. Structural Equation Modeling, 6, 1-55.

Karney, B. R., \& Bradbury, T. N. (1995). The longitudinal course of marital quality and stability: A review of theory, method, and research. Psychological Bulletin, 118, 3-34.

Karney, B. R., \& Bradbury, T. N. (1997). Neuroticism, marital interaction, and the trajectory of marital satisfaction. Journal of Personality and Social Psychology, 72, 1075-1092.

Kenny, D. A., Kashy, D. A., \& Cook, W. L. (2006). Dyadic data analysis. New York, NY: Guilford Press. 
Kling, K. C., Hyde, J. S., Showers, C. J., \& Buswell, B. N. (1999). Gender differences in selfesteem: A meta-analysis. Psychological Bulletin, 125, 470-500.

Kurdek, L. A. (2005). Gender and marital satisfaction early in marriage: A growth curve approach. Journal of Marriage and Family, 67, 68-84.

Kuster, F., \& Orth, U. (2013). The long-term stability of self-esteem: Its time-dependent decay and nonzero asymptote. Personality and Social Psychology Bulletin, 39, 677-690.

Kuster, F., Orth, U., \& Meier, L. L. (2013). High self-esteem prospectively predicts better work conditions and outcomes. Social Psychological and Personality Science, 4, 668-675.

Lavner, J. A., \& Bradbury, T. N. (2010). Patterns of change in marital satisfaction over the newlywed years. Journal of Marriage and Family, 72, 1171-1187.

Lavner, J. A., \& Bradbury, T. N. (2012). Do cold feet warn of trouble ahead? Premarital uncertainty and four-year marital outcomes. Journal of Family Psychology, 26, 10121017.

Lavner, J. A., Bradbury, T. N., \& Karney, B. R. (2012). Incremental change or initial differences? Testing two models of marital deterioration. Journal of Family Psychology, 26, 606-616.

Ledermann, T., \& Kenny, D. A. (2012). The common fate model for dyadic data: Variations of a theoretically important but underutilized model. Journal of Family Psychology, 26, 140148.

Ledermann, T., \& Macho, S. (2014). Analyzing change at the dyadic level: The common fate growth model. Journal of Family Psychology, 28, 204-213.

MacCallum, R. C., Browne, M. W., \& Cai, L. (2006). Testing differences between nested covariance structure models: Power analysis and null hypotheses. Psychological Methods, 11, 19-35.

Markides, K. S., Roberts-Jolly, J., Ray, L. A., Hoppe, S. K., \& Rudkin, L. (1999). Changes in 
marital satisfaction in three generations of Mexican Americans. Research on Aging, 21, $36-45$.

McArdle, J. J. (1988). Dynamic but structural equation modeling of repeated measure data. In J. R. Nesselroade \& R. B. Cattell (Eds.), Handbook of multivariate experimental data (Vol. 2, pp. 561-614). New York, NY: Plenum Press.

Meeks, B. S., Hendrick, S. S., \& Hendrick, C. (1998). Communication, love and relationship satisfaction. Journal of Social and Personal Relationships, 15, 755-773.

Meier, L. L., Orth, U., Denissen, J. J. A., \& Kühnel, A. (2011). Age differences in stability, contingency, and level of self-esteem across the life span. Journal of Research in Personality, 45, 604-612.

Murray, S. L., Holmes, J. G., Bellavia, G. M., Griffin, D. W., \& Dolderman, D. (2002). Kindred spirits? The benefit of egocentrism in close relationships. Journal of Personality and Social Psychology, 82, 563-581.

Murray, S. L., Holmes, J. G., \& Griffin, D. W. (1996). The benefits of positive illusions: Idealization and the construction of satisfaction in close relationships. Journal of Personality and Social Psychology, 70, 79-98.

Murray, S. L., Holmes, J. G., \& Griffin, D. W. (2000). Self-esteem and the quest for felt security: How perceived regard regulates attachment processes. Journal of Personality and Social Psychology, 78, 478-498.

Muthén, L. K., \& Muthén, B. O. (2010). Mplus user's guide: Sixth edition. Los Angeles, CA: Muthén and Muthén.

Orbuch, T. L., House, J. S., Mero, R. P., \& Webster, P. S. (1996). Marital quality over the life course. Social Psychology Quarterly, 59, 162-171.

Orth, U., Robins, R. W., \& Widaman, K. F. (2012). Life-span development of self-esteem and its 
effects on important life outcomes. Journal of Personality and Social Psychology, 102, 1271-1288.

Orth, U., Trzesniewski, K. H., \& Robins, R. W. (2010). Self-esteem development from young adulthood to old age: A cohort-sequential longitudinal study. Journal of Personality and Social Psychology, 98, 645-658.

Preacher, K. J., Wichman, A. L., MacCallum, R. C., \& Briggs, N. E. (2008). Latent growth curve modeling. Los Angeles, CA: Sage.

Radloff, L. S. (1977). The CES-D Scale: A self-report depression scale for research in the general population. Applied Psychological Measurement, 1, 385-401.

Robins, R. W., Hendin, H. M., \& Trzesniewski, K. H. (2001). Measuring global self-esteem: Construct validation of a single-item measure and the Rosenberg Self-Esteem Scale. Personality and Social Psychology Bulletin, 27, 151-161.

Rosenberg, M. (1965). Society and the adolescent self-image. Princeton, NJ: Princeton University Press.

Schafer, J. L., \& Graham, J. W. (2002). Missing data: Our view of the state of the art. Psychological Methods, 7, 147-177.

Shackelford, T. K. (2001). Self-esteem in marriage. Personality and Individual Differences, 30, 371-390.

Shaver, P. R., Schachner, D. A., \& Mikulincer, M. (2005). Attachment style, excessive reassurance seeking, relationship processes, and depression. Personality and Social Psychology Bulletin, 31, 343-359.

Spanier, G. B. (1976). Measuring dyadic adjustment: New scales for assessing the quality of marriage and similar dyads. Journal of Marriage and Family, 38, 15-28.

Swann, W. B., \& Bosson, J. K. (2010). Self and identity. In S. T. Fiske, D. T. Gilbert \& G. 
Lindzey (Eds.), Handbook of social psychology (Vol. 1, pp. 589-628). Hoboken, NJ: Wiley.

Sweet, J. A., \& Bumpass, L. L. (2002). The National Survey of Families and Households, 20012003, Wave III [Data file and codebook]. Madison, WI: University of Wisconsin, Center for Demography and Ecology [Distributor].

Trzesniewski, K. H., Donnellan, M. B., \& Robins, R. W. (2003). Stability of self-esteem across the life span. Journal of Personality and Social Psychology, 84, 205-220.

Vaillant, C. O., \& Vaillant, G. E. (1993). Is the U-Curve of marital satisfaction an illusion? A 40year study of marriage. Journal of Marriage and Family, 55, 230-239.

VanLaningham, J., Johnson, D. R., \& Amato, P. (2001). Marital happiness, marital duration, and the U-shaped curve: Evidence from a five-wave panel study. Social Forces, 78, 13131341.

Widaman, K. F., Ferrer, E., \& Conger, R. D. (2010). Factorial invariance within longitudinal structural equation models: Measuring the same construct across time. Child Development Perspectives, 4, 10-18.

Williamson, H. C., Ju, X., Bradbury, T. N., Karney, B. R., Fang, X., \& Liu, X. (2012). Communication behavior and relationship satisfaction among American and Chinese newlywed couples. Journal of Family Psychology, 26, 308-315.

Wirth, R. J., \& Edwards, M. C. (2007). Item factor analysis: Current approaches and future directions. Psychological Methods, 12, 58-79.

Zeigler-Hill, V. (2010). The interpersonal nature of self-esteem: Do different measures of selfesteem possess similar interpersonal content? Journal of Research in Personality, 44, $22-$ 30. 


\section{Footnotes}

${ }^{1}$ Although for identification purposes it would be sufficient to fix the loadings for one of the partners, fixing both loadings provides for more stable solutions when only two indicators are available per latent factor (Kenny, Kashy, \& Cook, 2006).

${ }^{2}$ We also tested a bivariate growth curve model in which men and women had separate growth factors for relationship satisfaction. The model fit was good $(\mathrm{TLI}=.98, \mathrm{CFI}=.98$, RMSEA = .045). However, given that both the common fate growth model and the bivariate growth model provided a good fit, we used the simpler model (i.e., the common fate growth model) for the analyses.

${ }^{3}$ Although the coefficients were constrained to be equal across gender, the constraints were imposed on unstandardized coefficients (as typically recommended), which led to slight variation in the resulting standardized coefficients.

${ }^{4}$ As in Study 1, we also tested a bivariate growth curve model in which men and women had separate growth factors for relationship satisfaction. The fit was acceptable $(\mathrm{TLI}=.80, \mathrm{CFI}=$ .95 , RMSEA $=.076)$. However, given that both the common fate growth model and the bivariate growth model provided an acceptable fit, we used the simpler model (i.e., the common fate growth model) for the analyses.

${ }^{5}$ To allow for convergence of the model, we constrained the variances of the growth factors to be equal across groups.

${ }^{6}$ To allow for convergence of the model, we constrained the variances of the growth factors to be equal across groups and in the Hispanic group we fixed the correlation between the partners' self-esteem slopes to the value of the model with cross-group constraints. 
Table 1

Means and Standard Deviations of Self-Esteem and Relationship Satisfaction Across Waves, Separately for Men and Women

\begin{tabular}{ccccc}
\hline & \multicolumn{2}{c}{ Self-esteem } & \multicolumn{2}{c}{ Relationship satisfaction } \\
\cline { 2 - 5 } & Men & Women & Men & Women \\
\hline Study 1 (LSG) & $3.52(0.45)$ & $3.52(0.44)$ & $3.90(0.64)$ & $3.91(0.70)$ \\
Time 1 & $3.55(0.44)$ & $3.53(0.43)$ & $3.89(0.70)$ & $3.89(0.76)$ \\
Time 2 & $3.35(0.43)$ & $3.31(0.42)$ & $3.89(0.66)$ & $3.91(0.67)$ \\
Time 3 & $3.36(0.41)$ & $3.32(0.42)$ & $3.96(0.64)$ & $3.92(0.74)$ \\
Time 4 & $3.36(0.45)$ & $3.33(0.44)$ & $3.98(0.64)$ & $3.98(0.67)$ \\
Time 5 & & & \\
Study 2 (NSFH) & $4.10(0.57)$ & $4.11(0.60)$ & $6.12(1.19)$ & $6.05(1.28)$ \\
Time 1 & $4.12(0.61)$ & $4.03(0.64)$ & $5.95(1.28)$ & $5.91(1.34)$ \\
Time 2 & $4.08(0.57)$ & $4.04(0.58)$ & $6.19(1.06)$ & $6.13(1.16)$ \\
Time 3 & & & & \\
\hline
\end{tabular}

Note. Values shown in parentheses are standard deviations. In Study 1, the response scales ranged from 1 to 4 for self-esteem and from 1 to 5 for relationship satisfaction. In Study 2, the response scales ranged from 1 to 5 for self-esteem and from 1 to 7 for relationship satisfaction. LSG = Longitudinal Study of Generations; NSFH = National Survey of Families and Households. 


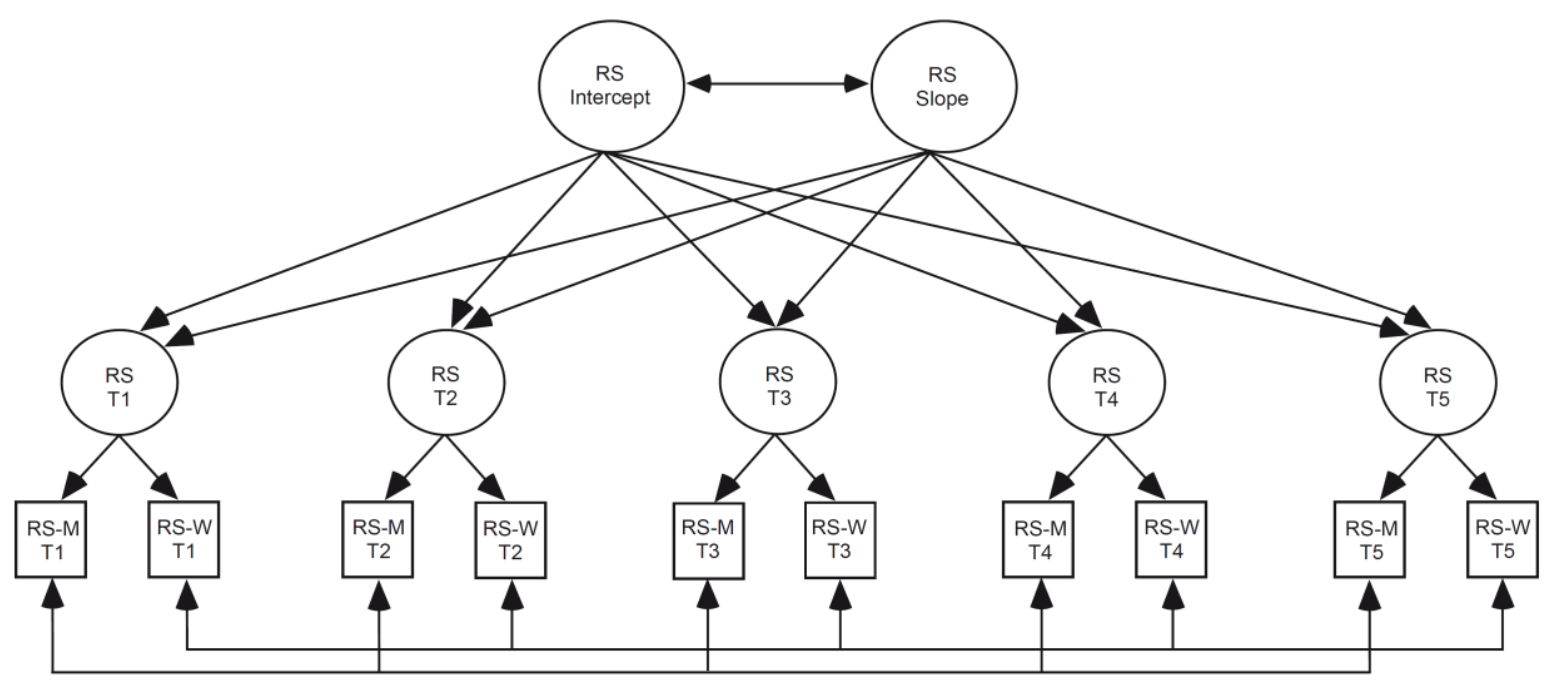

Figure 1. Generic model used for the common fate growth curve model for relationship satisfaction. RS = relationship satisfaction; RS-M = men's relationship satisfaction; $\mathrm{RS}-\mathrm{W}=$ women's relationship satisfaction; T1 to T5 = Time 1 to Time 5 . 


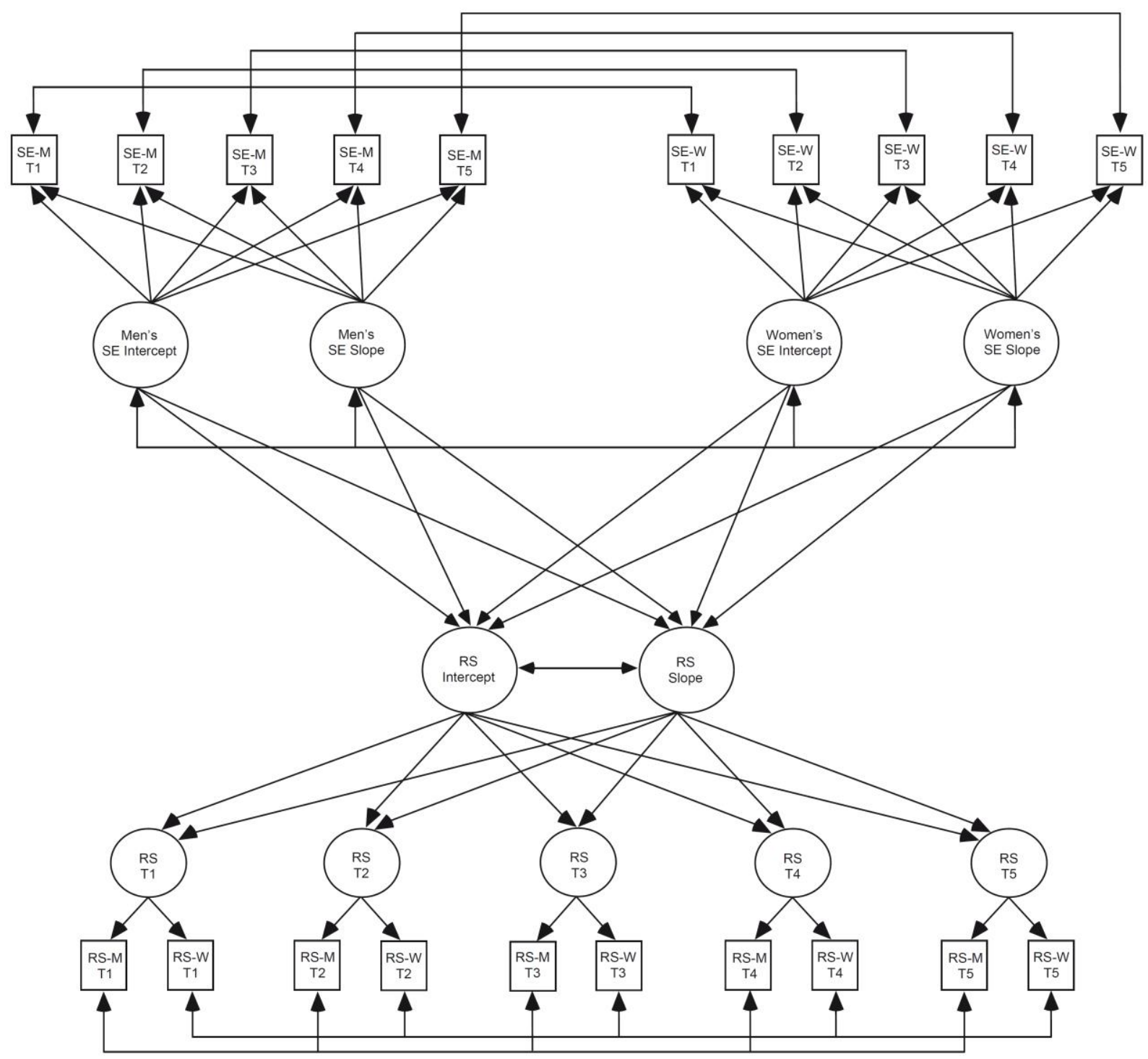

Figure 2. Generic model used for the analysis of the effects of men's and women's growth factors for self-esteem on the growth factors for relationship satisfaction. The model controls for the effects of age and length of relationship, by regressing the growth factors for self-esteem and relationship satisfaction on the control variables (not shown in the figure). SE = self-esteem; SE$\mathrm{M}=$ men's self-esteem; $\mathrm{SE}-\mathrm{W}=$ women's self-esteem; $\mathrm{RS}=$ relationship satisfaction; $\mathrm{RS}-\mathrm{M}=$ men's relationship satisfaction; RS-W = women's relationship satisfaction; T1 to T5 = Time 1 to Time 5. 
A Longitudinal Study of Generations

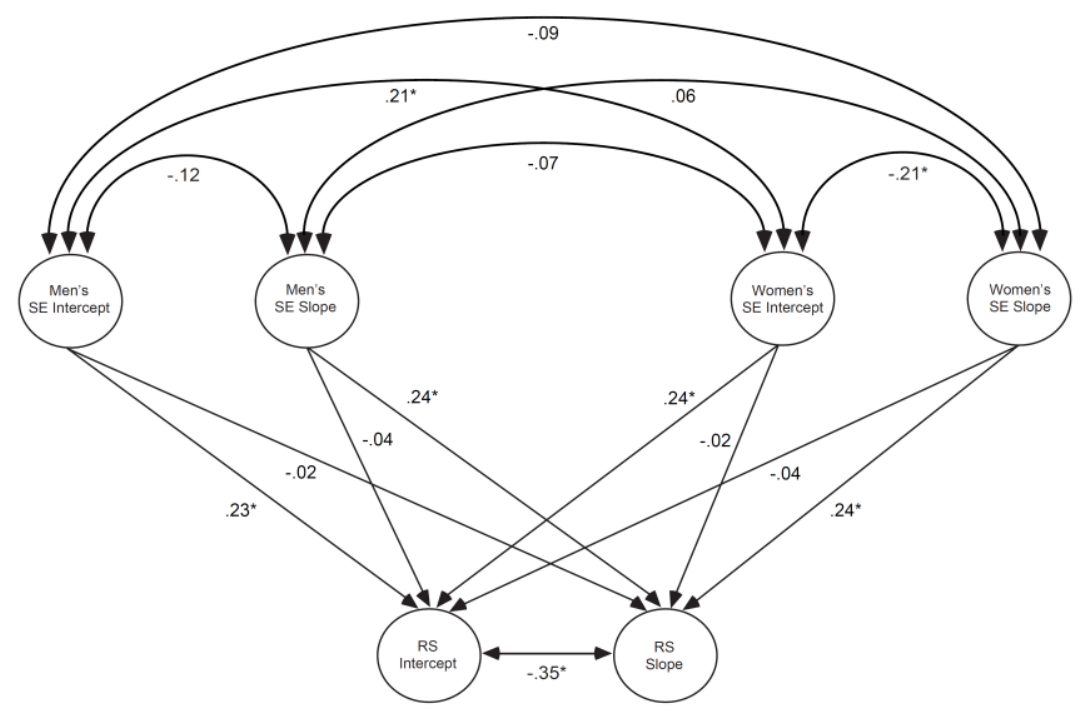

B National Survey of Families and Households

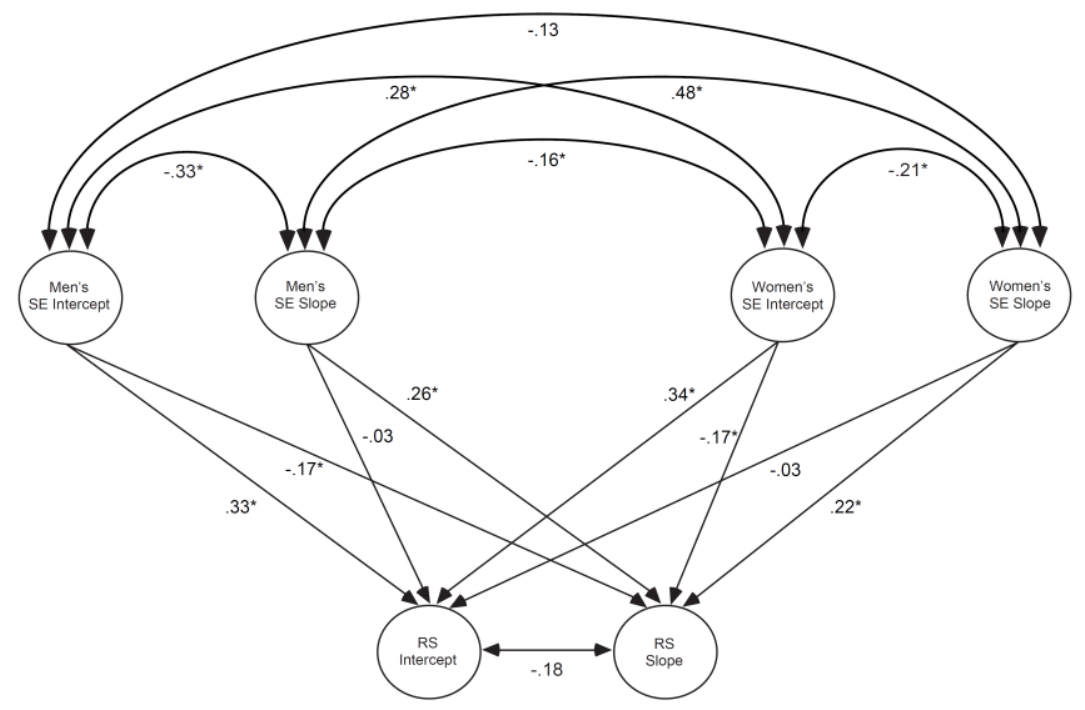

Figure 3. Standardized estimates of self-esteem predicting relationship satisfaction in Study 1

(Panel A) and Study 2 (Panel B). The models control for the effects of age and length of relationship, by regressing the growth factors for self-esteem and relationship satisfaction on the control variables (not shown in the figure). $\mathrm{SE}=$ self-esteem; $\mathrm{RS}=$ relationship satisfaction. ${ }^{*} p<$ .05 . 